\title{
Removal of Lead Ions from Wastewater Using Functionalized Multiwalled Carbon Nanotubes with Tris(2-Aminoethyl)Amine
}

\author{
Mohammad Saber Tehrani ${ }^{1 *}$, Parviz Abroomand Azar ${ }^{1}$, Parvin Ehsani Namin ${ }^{1}$, \\ Shahram Moradi Dehaghi ${ }^{2}$ \\ ${ }^{1}$ Department of Chemistry, Science and Research Branch of Islamic Azad University, Tehran, Iran; ${ }^{2}$ Faculty of Chemistry, Tehran \\ North Branch of Islamic Azad University, Tehran, Iran. \\ Email: "drmsabertehrani@yahoo.com
}

Received April 14 ${ }^{\text {th }}, 2013$; revised May $16^{\text {th }}, 2013$; accepted June $13^{\text {th }}, 2013$

Copyright (C) 2013 Mohammad Saber Tehrani et al. This is an open access article distributed under the Creative Commons Attribution License, which permits unrestricted use, distribution, and reproduction in any medium, provided the original work is properly cited.

\begin{abstract}
Recently, many attempts have been made to use carbon nanotubes in analytical chemistry, especially in adsorption of heavy metal ions from water. In this study, multiwalled carbon nanotubes (MWCNTs) were functionalized with tris(2aminoethyl) amine. The functionalized nanoparticles were characterized using Fourier transform infrared (FTIR), thermal gravimetric analyzer (TGA), elemental analysis, and Raman spectroscopy. The results revealed that the functionalization reaction was successfully accomplished. Lead adsorption from water was carried out using functionalized MWCNTs and measured by flame atomic absorption spectrometry (FAAS). The effects of pH, shaking time, initial metal ion concentration, and adsorbent dosage on the adsorption process were studied via batch method. The results obtained showed that removal of lead ions strongly depended on the $\mathrm{pH}$. Desorption study revealed that lead ions adsorbed on the functionalized MWCNTs could be desorbed at $\mathrm{pH}<3$ due to breakage of complexes formed on the sorbent surface. Maximum adsorption capacity of the sorbent under the optimal conditions was $43 \mathrm{mg} / \mathrm{g}$. This favorable adsorption capacity suggests that functionalized carbon nanotubes can be applied for removal of lead from water solutions. The data obtained were fitted with the Langmuir and Freundlich isotherm adsorption models and Langmuir model showed better agreement with the experimental data.
\end{abstract}

Keywords: Functionalized Multiwalled Carbon Nanotubes; Tris(2-Aminoethyl)Amine; Lead Adsorption; Isotherm Adsorption Models

\section{Introduction}

Carbon nanotubes as a new type of materials from carbon family have a coaxial cylindrical form, composed of graphene sheets within nanometer size in diameter and micrometer size in length [1,2]. These materials are classified to single-walled (SWCNTs) and multiwalled (MWCNTs) carbon nanotubes. These different groups of nanotubes do not show the same properties. Unique physical and chemical properties such as high surface area, chemical stability, mechanical strength, low density, thermal stability, and electrical properties have reported for carbon nanotubes in different applications [3-8]. Strong adsorption capacity is the main reason for using these

"Corresponding author. materials in analytical chemistry; especially in removing environmental pollutants such as phenols [9], diazinon [10], diuron [11], atrazine [12], organo phosphorus compounds [13], rhodium [14], zinc [15], chromium [16,17], nickel [18] and lead [19-21].

Lead is the most important pollutant entering human life through industrial wastewater and causes different illnesses. Due to non-degradability of lead, many attempts have done to remove this pollutant from the environment. Various methods including precipitation, liquid-liquid extraction, membrane filtration, ion exchange, and adsorption have been used for separation of lead from different waters. Among the above-mentioned methods, adsorption is a principle method for removal of heavy metals from environmental waters, because of its efficiently 
and simplicity. Many efforts have been focused on finding new adsorbents with higher adsorption capacity.

Carbon nanotubes can be a beneficial sorbent. However, the raw ones are rarely used for sorption of ion metals owing to van der Waals interactions among carbon atoms in graphene sheets. In contrast, modified carbon nanotubes are better sorbents for extraction of metal ions from various samples, because functionalization not only improves dispersion in the media but also increases sorption metal ions through chemical bonding, which would be more selective than raw carbon nanotubes. Thus, functionalization by chemical groups has been considered by the researchers $[22,23]$. In general, some modifications on the surface of carbon nanotubes are firstly made by strong acids by introducing carboxyl, hydroxyl, and carbonyl groups on the surface of carbon nanotubes [23-25]. Further modifications are accomplished by various molecules that can be grafted through creation of amide, ester, and amine bonds. Typical molecules reported in the literature as functionalization agents are 1-(2-pyridylazo)-2-naphtol [26], thiosemicarbazide [27], 2-aminobenzothiazole [20], phenyl-iminodiaceticacid [28], ethyenediamine [29], diethylenetriamine, triethylenetetrami [30], poly(2-aminothiophenol) [31], and tris(2-aminoethyl)amine [32].

This study is motivated by the current researches in the field of adsorption of heavy metal ions using functionalized carbon nanotubes. The aim of this work was preparation of functionalized MWCNTs with tris(2-aminoethyl) amine (MWCNTs-TAA). The potential of the functionalized MWCNTs obtained was evaluated using FAAS as an adsorbent for lead. The effects of $\mathrm{pH}$ value, sorbent dosage, and shaking time on the adsorption process were determined. Adsorption capacity was measured via the batch method. The data obtained were simulated by Langmuir and Freundlich isotherm models.

\section{Experimental}

\subsection{Materials}

MWCNTs was obtained from Cheaptubes Inc. (USA) with $10-20 \mathrm{~nm}$ in outer diameter, $30 \mathrm{~nm}$ in length, and $>95 \%$ purity. All other reagents such as concentrated $\mathrm{HNO}_{3}$, thionyl chloride $\left(\mathrm{SOCl}_{2}\right)$, dimethyl formamide (DMF), dichloromethane (DCM), triethylamine, and tris (2-aminoethyl) amine were provided from Sigma Aldrich.

Metal stock solution $\left(1000 \mathrm{mg} \cdot \mathrm{L}^{-1}\right)$ of $\mathrm{pb}(\mathrm{II})$ was prepared by dissolving its nitrate salt (analytical grade) in deionized water. The solution was further diluted to the required concentrations for the sorption measurements. Laboratory glassware used were repeatedly cleaned with $5 \% \mathrm{v} / \mathrm{v} \mathrm{HNO}_{3}$ and rinsed with deionized water.

\subsection{Instruments and Apparatus}

A Varian Model spectra AA.200 atomic absorption spectrometer equipped with single element hollow cathode (HCL) lamps, deuterium background correction, and airacetylene was used for pb(II) measurements. Lead HCL was used as the radiation sources at the wavelength of $217 \mathrm{~nm}$. The instrumental parameter adjustments were those recommended by the manufacturer.

Thermogravimetry analysis (TGA) was conducted by a TGA-7HT from Perkin Elmer (USA) under $\mathrm{N}_{2}$ and in the range of $25^{\circ} \mathrm{C}-700^{\circ} \mathrm{C}$ at the heating rate of $10^{\circ} \mathrm{C} / \mathrm{min}$.

Infrared spectra were recorded on an EQUINOX 55 FTIR spectrometer. The $\mathrm{pH}$ values were adjusted with a Metrohm digital $\mathrm{pH}$ meter. The Raman spectra was obtained by a Raman Spectrometer; Model Almega Thermo Nicolet Dispersive Raman Spectrometer.

Elemental analysis of functionalized samples was applied using Vario EL III Analysen systeme GmbH.

\subsection{Oxidized MWCNTs Preparation (MWCNT-COOH)}

Oxidized MWCNTs were prepared by oxidation with 3M $\mathrm{HNO}_{3}$. Predetermined quantities of raw MWCNTs and $250 \mathrm{ml} \mathrm{HNO}_{3}$ were dispersed for $30 \mathrm{~min}$ in an ultrasonic bath $(35 \mathrm{KHz}, 70 \mathrm{~W})$. The reaction flask equipped with a reflux condenser, a magnetic stirrer and a thermometer was mounted in the oil bath. The suspension was then stirred at $110^{\circ} \mathrm{C}$ for $48 \mathrm{~h}$. The mixture was cooled to the room temperature and was vacuum filtered. The mixture was then washed with deionized water until a neutral $\mathrm{pH}$ of the filtrate was reached. The oxidized MWCNTs were dried in a vacuum oven at $105^{\circ} \mathrm{C}$ overnight.

\subsection{Synthesis of MWCNTs-TAA}

The $500 \mathrm{mg}$ MWCNTs-COOH was suspended in $20 \mathrm{ml}$ thionyl chloride and stirred at $70^{\circ} \mathrm{C}$ for $24 \mathrm{~h}$. Using DCM, the mixture was diluted and filtered under vacuum condition. Washing by DCM was continued until the filtrate became colorless.

The solid filtrate (MWCNTs-COCl) obtained was dried in a vacuum oven at $40^{\circ} \mathrm{C}$. In the next step, the dried MWCNTs-COCl was dispersed into $50 \mathrm{ml}$ anhydrous DMF, and then $15 \mathrm{ml}$ tris(2-aminoethyl) amine and $3 \mathrm{ml}$ triethylamine were added. The mixture left to stir at $50^{\circ} \mathrm{C}$ for $48 \mathrm{~h}$. The mixture obtained was filtered through an appropriate filter. To remove the unreacted materials, the filtrate was washed by DMF until the colorless DMF was observed. Finally, the filtrate was washed by ethanol and put under vacuum oven at $80^{\circ} \mathrm{C}$ for $12 \mathrm{~h}$.

\subsection{Batch Method Procedure}

Batch adsorption experiments were performed using a 
portion of the sample solutions $(10 \mathrm{~mL})$ including $\mathrm{pb}(\mathrm{II})$ ions, transferred into a triangular flask. The $\mathrm{pH}$ values of the solutions were adjusted using $\mathrm{HNO}_{3}$ or $\mathrm{NaOH}$ with $(0.1-0.01) \mathrm{mol} \cdot \mathrm{L}^{-1}$ concentration. Then, $10 \mathrm{mg}$ of the adsorbent was added to the solution and the mixture was shaken at $150 \mathrm{rpm}$ for $45 \mathrm{~min}$. The mixture was filtered after centrifuge at $1500 \mathrm{rpm}$ for $20 \mathrm{~min}$. The concentration of $\mathrm{pb}(\mathrm{II})$ ions in the solution was determined by FAAS.

The percentage of removed $\mathrm{pb}(\mathrm{II})$ ions (R) was determined as follows [33]:

$$
\% R=\frac{C_{0-} C_{\mathrm{t}}}{C_{0}} \times 100
$$

where $C_{0}$ is the initial concentration of $\mathrm{pb}$ (II) ions in $\mathrm{mg} \cdot \mathrm{L}^{-1}, C_{\mathrm{t}}$ is the concentration of $\mathrm{pb}(\mathrm{II})$ ions at time $\mathrm{t}$ in $\mathrm{mg} \cdot \mathrm{L}^{-1}$.

\section{Results and Discussion}

\subsection{Characterization of Functionalized MWCNTs}

The FTIR spectra of pristine MWCNTs and MWCNTs$\mathrm{COOH}$ and MWCNTs-TAA are illustrated in Figure 1. In the FTIR spectrum of MWCNTs-COOH, the peaks at 3415 and $1620 \mathrm{~cm}^{-1}$ can be attributed to the stretching vibrations of $\mathrm{O}-\mathrm{H}$ and $\mathrm{C}=\mathrm{O}$ of carboxyl groups, respectively. In addition, the peak at $1080 \mathrm{~cm}^{-1}$ is assigned to the $\mathrm{C}-\mathrm{O}$ stretching vibration. Presence of these peaks suggests that oxidation of the MWCNTs have introduced $\mathrm{COOH}$ groups on the surface of MWCNTs. Similar results have reported by G. D. Vukovic [29,30].

In the FTIR spectrum of MWCNT-TAA a peak appears at $1580 \mathrm{~cm}^{-1}$, which is originated from C-N stretching and $\mathrm{N}-\mathrm{H}$ bending vibration [32]. Existence of this bond implies grafting of TAA on the MWCNT-COOH.

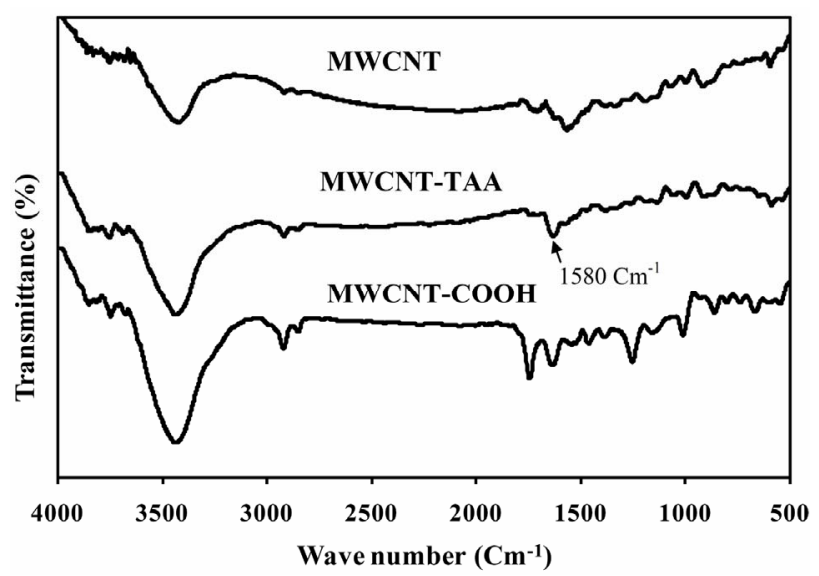

Figure 1. FTIR spectra of MWCNT, MWCNT-TAA, and MWCNT-COOH.
TGA gives useful information about the MWCNTsTAA structure because the pristine MWCNT is stable and hardly decompose below $700^{\circ} \mathrm{C}$ while the weight of MWCNTs-COOH and MWCNTs-TAA decrease. Thermograms of MWCNTs-COOH and MWCNTs-TAA are demonstrated in Figure 2. As can be seen in this Figure, MWCNTs-COOH decomposition occurs gradually in the whole range of temperature. The trend of weight loss for MWCNTs-TAA is moderate and faster than that of MWCNTs-COOH up to $450^{\circ} \mathrm{C}$ due to decomposition of TAA. Above $450^{\circ} \mathrm{C}$, the decomposition rate of MWCNTsTAA is slow and may be attributed to degradation of unreacted - $\mathrm{COOH}$ groups. Residuals of the oxidized carbon nanotube and MWCNTs-TAA at $450^{\circ} \mathrm{C}$ were 6 and 9 $\mathrm{wt} \%$, respectively. The results of elemental analysis are embedded in thermograms. Existence of nitrogen in MWCNTs-TAA is a sign of successful functionalization of TAA on the MWCNTs surface. The percentage of N in MWCNTs-TAA is in agreement with TGA thermograms. In other words, the percentage of $\mathrm{N}$ shows the presence of almost $8 \%$ TAA in MWCNTs-TAA, which is approximately equal to the weight loss in the thermogram.

Raman spectroscopy is a valid method to track the carbon nanotube surface modification, which have used by researchers [32,34,35]. Figure 3 shows Raman spectra of MWCNTs-COOH and MWCNTs-TAA. As can be seen, the main peaks in the Raman spectra are D and G bonds at 1339 and $1580 \mathrm{~cm}^{-1}$, respectively. D band is attributed to disordered carbon atoms of MWCNTs corresponding to $\mathrm{sp}^{3}$-hybridized and $\mathrm{G}$ band is related to the $\mathrm{sp}^{2}$-hybridized carbon atoms. Area ratio of the $\mathrm{D}$ and $\mathrm{G}$ bands were 1.27 for MWCNTs-COOH and 1.5 for MWCNTs-TAA. This gradual alteration is an indication for the occurrences of MWCNTs-COOH conversion to MWCNTs-TAA.

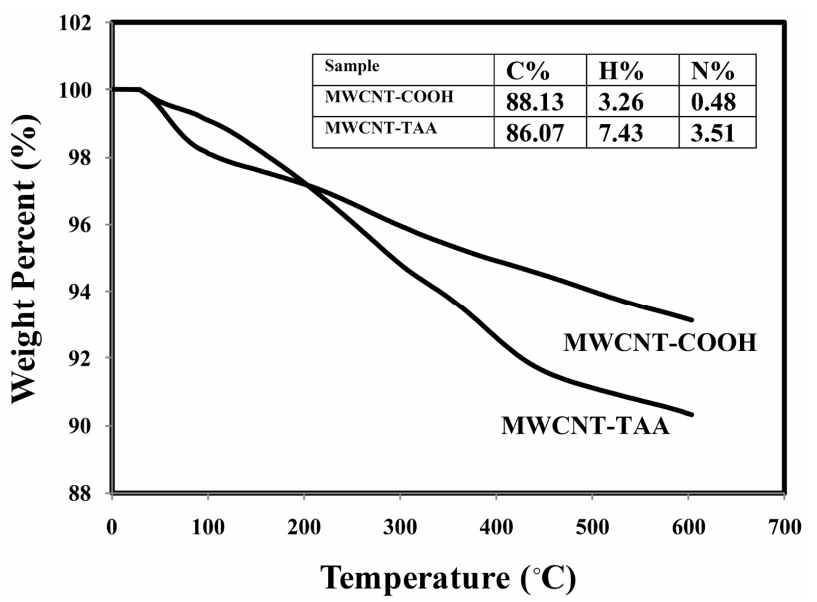

Figure 2. TGA thermogram of MWCNT-COOH and MWCNT-TAA. 


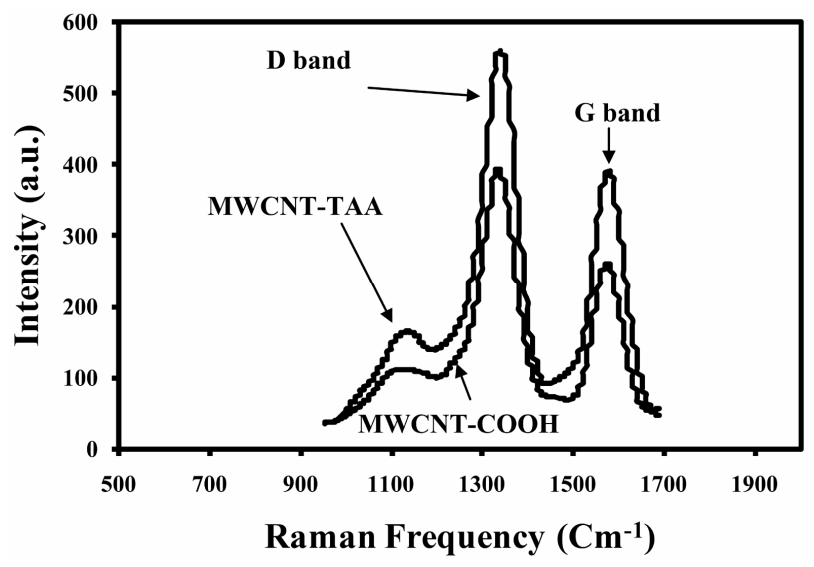

Figure 3. Raman spectra of MWCNT-COOH and MWCNTTAA.

\subsection{Assessment of Adsorption}

\subsubsection{Effect of $\mathbf{p H}$}

One of the most important analytical factors in adsorption of metal ions is the $\mathrm{pH}$ value, owing to its effect on solubility of metal ions, surface charge adsorbent and degree of protonation of binding sites of the chelating molecules on adsorbate during the reaction [36,37]. To evaluate the effect of $\mathrm{pH}$ on the lead adsorption, experiments were carried out with solutions of initial concentration at several $\mathrm{pH}$ values in the range of $3-11$ using either $\mathrm{NaOH}\left(0.01-0.1 \mathrm{~mol} \cdot \mathrm{L}^{-1}\right)$ or $\mathrm{HNO}_{3}(0.01-0.1$ $\mathrm{mol} \cdot \mathrm{L}^{-1}$ ) for $\mathrm{pH}$ adjustment.

Four probable forms of lead at different $\mathrm{pH}$ values exist that are $\mathrm{Pb}^{2+}, \mathrm{Pb}(\mathrm{OH})^{+}, \mathrm{Pb}(\mathrm{OH})_{2}$, and $\mathrm{Pb}(\mathrm{OH})^{3-}$ [38]. At $\mathrm{PH}<6$, the dominant form of the lead is $\mathrm{Pb}^{2+}$ while with increase in $\mathrm{pH}$ value, other forms are created. It is clear that sorption initiates from $\mathrm{pH}=3$ and there is no adsorption below this $\mathrm{pH}$ value. This trend can be attributed to competition between $\mathrm{H}^{+}$and $\mathrm{Pb}^{2+}$ ions for capturing the active sites. The favorite mechanism in this system is reaction between electron lone pair in nitrogen of the TAA groups and metals ion, which results in formation of metal complex. While in acidic solution $(\mathrm{pH}<$ 3 ), the active sites of TAA (electron lone pair) is protonated and inhibited from reaction with $\mathrm{Pb}^{2+}$.

Figure 4 shows the removal percentage versus $\mathrm{pH}$. As seen in this Figure, the best removal occurred in the $\mathrm{pH}$ range of $5.7-6$. By considering the precipitation constant $\left(1.2 \times 10^{-12}\right)$ and the initial concentration $\left(C_{0}=10 \mathrm{mg} / \mathrm{L}\right)$, the main reason for the best recovery in this $\mathrm{pH}$ range is dominant presence of $\mathrm{Pb}^{2+}$. In other words, above this range, there is interference between precipitation and adsorption and one cannot claim that the pb(II) removal is only accomplished by the sorbent.

\subsubsection{Desorption and Reusability}

To check the reusability of MWCNTs-TAA, adsorption experiments were done at initial $\mathrm{pb}^{2+}$ concentration of 20 $\mathrm{mg} \cdot \mathrm{L}^{-1}$ (similar to the batch method described). When adsorption completely occurred, MWCNT-TAA was dried at $50^{\circ} \mathrm{C}$ for $3 \mathrm{~h}$ and then dispersed in deionized water at $\mathrm{pH}<2$ (using $\mathrm{HNO}_{3}$ ). After sonication, removal $\mathrm{pb}^{+2}$ from MWCNTs-TAA were filtrated and measured. After regeneration of the adsorbent, it was washed with deionized water and used in further adsorption-desorption testes. These procedures were repeated four times and the results revealed that the sorbent ability after regeneration did not change considerably. The efficiency of lead removal was around $96 \%$ and decreased after the fourth adsorption-desorption cycle.

\subsubsection{Effect of Sorbent Amount}

In order to monitor the effect of sorbent amount on the adsorption process, all parameters considered (temperature, shaking time, concentration, and $\mathrm{pH}$ ) were kept constant except the sorbent amount, which varied in the range of $5-35 \mathrm{mg}$ in each sample. The results showed that $10 \mathrm{mg}$ of sorbent is sufficient for pb(II) extraction in the sample (Figure 5). Selection of sorbent below $10 \mathrm{mg}$ leads to incomplete adsorption and therefore in all experiments $10 \mathrm{mg}$ of sorbent was chosen.

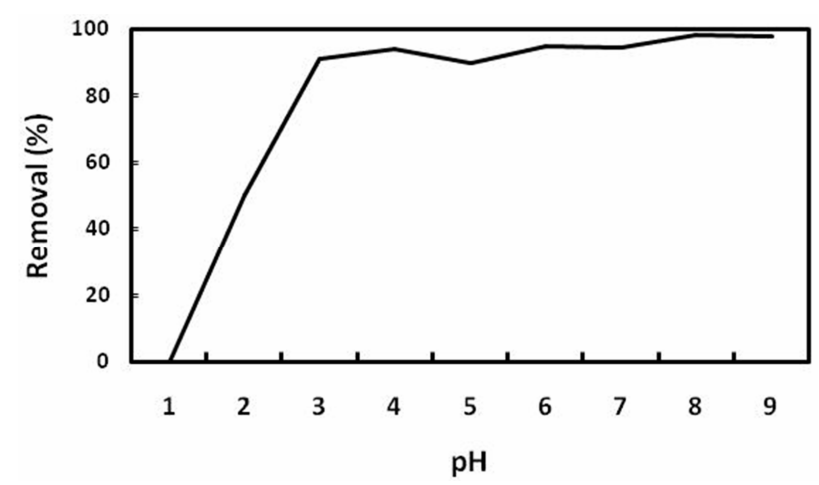

Figure 4. Removal percentage of $\mathrm{pb}(\mathrm{II})$ ions at different $\mathrm{pH}$ values.

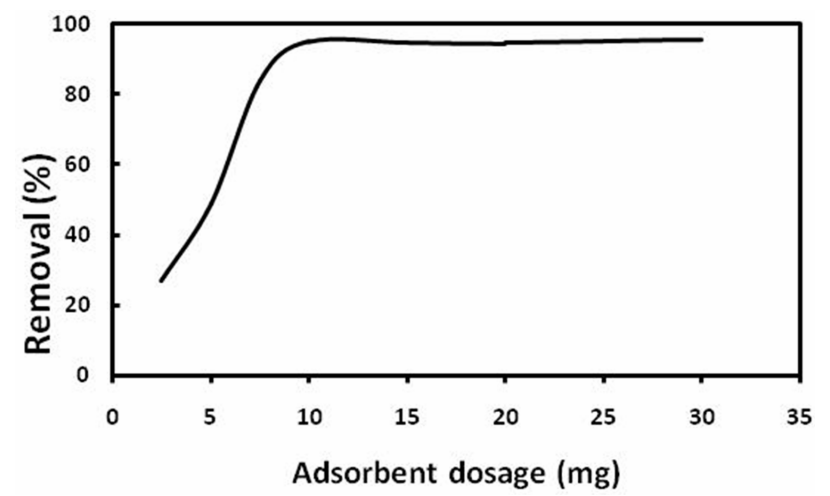

Figure 5. Removal percentage of $\mathrm{pb}$ (II) ions at different adsorbent dosages. 


\subsubsection{Effect of Shaking Time}

Shaking time is a reflection of adsorption rate, which determines the time required for perfect adsorption. Different shaking times in the range of $10-120 \mathrm{~min}$ were examined according to the batch method. Removal percentage of $\mathrm{pb}(\mathrm{II})$ versus shaking time is demonstrated in Figure 6. As seen, $96 \%$ of the adsorption was accomplished during $45 \mathrm{~min}$. This shaking time was selected for further experiments.

\subsubsection{Adsorption Capacity}

The amount of sorbent required for analyte extraction from the solution is determined by sorption capacity. For this purpose, $10 \mathrm{ml}$ of $\mathrm{pb}$ (II) solutions at their initial concentrations of $5-140 \mathrm{mg} / \mathrm{L}$ and $\mathrm{pH} 5.7$ - 6 were prepared and $10 \mathrm{mg}$ of MWCNTs-TAA was added to the solution. After $45 \mathrm{~min}$ of shaking, the solutions were separated from the adsorbent and lead ions were determined by FAAS. The amount of adsorbed metal ions per gram of adsorbent ( $Q$ in $\mathrm{mg} \cdot \mathrm{g}^{-1}$ ) versus the initial concentration $\left(C_{0}\right.$ in $\left.\mathrm{mg} \cdot \mathrm{L}^{-1}\right)$ is shown in Figure 7. Q was determined according to the following equation [28]

$$
Q=\left(C_{0}-C_{e}\right) V / M
$$

where $C_{e}$ is the equilibrium concentration of $\mathrm{pb}(\mathrm{II})$ in

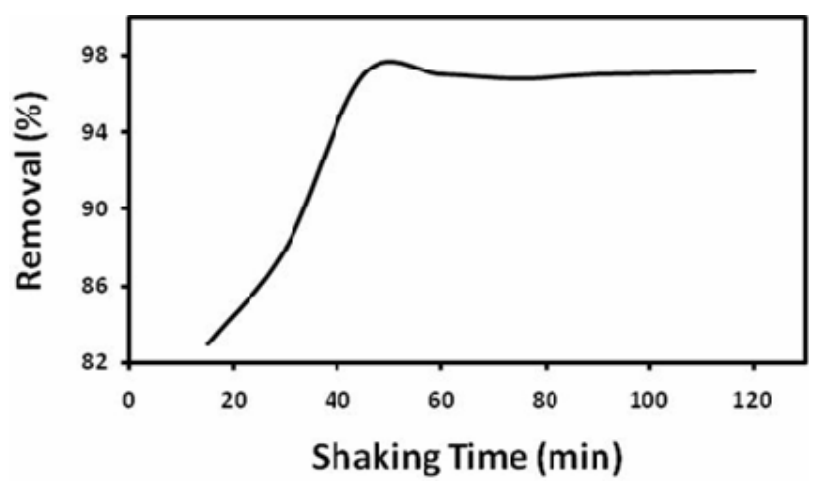

Figure 6. Removal percentage of $\mathrm{pb}(\mathrm{II})$ ions at different times.

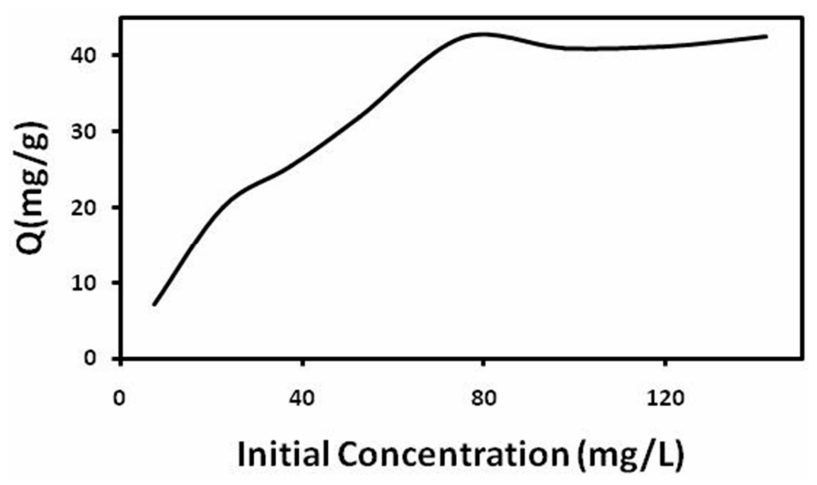

Figure 7. Adsorption capacity of pb(II) on MWCNT-TAA. $\mathrm{mg} \cdot \mathrm{L}^{-1}, M$ the adsorbent mass in $\mathrm{g}$, and $V$ is the volume of metal ion solutions in liter. Maximum adsorption capacities of MWCNTs-TAA was obtained for $43 \mathrm{mg} / \mathrm{g}$ of $\mathrm{pb}$ (II). To compare our results with those reported in the literature, the published data for different sorbents are given in Table 1. It is clear that in comparison with other sorbents, MWCNTs-TAA shows a reasonable and comparable performance.

\subsubsection{Interference Studies}

To clarify the effect of other ion metals on the MWCNTsTAA adsorption, the adsorption of $\mathrm{Ni}(\mathrm{II}), \mathrm{Zn}(\mathrm{II}), \mathrm{Co}(\mathrm{II})$, $\mathrm{Mn}(\mathrm{II}), \mathrm{Ni}(\mathrm{II})$ and $\mathrm{Cu}(\mathrm{II})$ were determined according to the batch method. The results obtained revealed that there was no adsorption for $\mathrm{Co}$ (II) and $\mathrm{Zn}$ (II) while $\mathrm{Ni}(\mathrm{II}), \mathrm{Mn}(\mathrm{II})$, and $\mathrm{Cu}(\mathrm{II})$ showed $6 \%, 20 \%$ and $47 \%$ adsorption, respectively. It seems that lead can be adsorbed selectively by this sorbent.

\subsection{Adsorption Isotherm}

The most famous isotherm models that are used to express the distribution of metal ions between solid and liquid phases are Langmuir and Freundlich [39-41]. The main assumption of Langmuir model is presence of monolayer coverage of the adsorbate on the adsorbent surface and there is the same activation energy for adsorption of every molecule on the surface.

The Langmuir expression is given by: [40]

$$
q=q_{m} \frac{K_{L} C}{1+K_{L} C}
$$

where $q$ and $q_{m}$ are the values of metal ions absorbed after equilibrium and the saturation capacity of the monolayer, respectively. $K_{L}$ is the Langmuir constant, which depends on the affinity of binding sites. $q_{m}$ and $K_{L}$ are determined from intercept and slope of $1 / q$ versus $1 / c$.

Freundlich isotherm originates from the multilayer adsorption model and expresses the adsorption on the heterogeneous surface. This model obeys [42]

$$
q=K_{f} C^{1 / n}
$$

where $q$ is the equilibrium concentration of $\mathrm{pb}(\mathrm{II})$ on the

Table 1. Comparison of adsorption capacity of MWCNTTAA with other sorbents.

\begin{tabular}{ccc}
\hline Adsorbent & Adsorption capacity $(\mathrm{mg} / \mathrm{g})$ & Reference \\
\hline Chelating resin & 7.38 & {$[43]$} \\
Activated carbon & 13.05 & {$[44]$} \\
Silica gel/gallic acid & 12.63 & {$[45]$} \\
Modified nanometer $\mathrm{SiO}_{2}$ & 6 & {$[46]$} \\
MWCNTs-TAA & 43 & This work \\
\hline
\end{tabular}


MWCNTs-TAA ( $\mathrm{mg} / \mathrm{g}), c$ is the equilibrium concentration of $\mathrm{pb}$ (II) in the solution, $K_{f}$ and $n$ are the Freundlich constants, which indicate the capacity and power of adsorption, respectively. Figure 8 illustrates lead isotherm adsorption on the MWCNTs-TAA. It is obvious that at first, the adsorption is relatively rapid while with increase in equilibrium concentration, the adsorption is leveled off. The maximum experimental value is obtained from this curve. In order to check the agreement of the aforesaid models with our experimental data, the adsorption isotherm is drawn based on the models and the important parameters are depicted in Table 2. As seen, the regression coefficient for the Langmuir model is greater than that of the Freundlich model, which means adsorption is in the monolayer form. In other words, our experimental data is in agreement with the Langmuir model. The maximum adsorption $\left(q_{m}\right)$ was $71 \mathrm{mg} / \mathrm{g}$, which indicates a good adsorption capacity for this sorbent.

\subsection{Application of MWCNTs-TAA for Real Samples}

The real sample was tap water of the analytical laboratory of Azad University in Tehran, Iran. Four samples containing $0,5,10$, and $15 \mathrm{ppm}$ of lead ion were spiked.

Then, $10 \mathrm{mg}$ of the adsorbent was added to the samples and their adsorptions were determined according to the above-mentioned process in previous experiments. All the experiments were accomplished in triplicate and the mean values were reported. The results are given in Table 3. Our evaluation showed that adsorption is not affected by the presence of $\mathrm{Ca}$ and $\mathrm{Mg}$ in the water samples. In other words, adsorption using MWCNTs-TAA is not influenced by the matrix.

\section{Conclusions}

This study is motivated by the current researches in assessment of the potential of carbon nanotubes in removal

Table 2. Constants of Langmuir and Freundlich models for adsorption of pb(II) onto MWCNTs-TAA.

\begin{tabular}{cccccc}
\hline$q_{m}$ & $K_{L}$ & $R^{2}$ & $n$ & $K_{f}$ & $R^{2}$ \\
\hline 71 & 0.1304 & 0.993 & 1.43 & 8.34 & 0.945 \\
\hline
\end{tabular}

Table 3. Removal(\%) of pb(II) after treating $10 \mathrm{~mL}$ of water with $0.01 \mathrm{mg}$ MWCNTs-TAA.

\begin{tabular}{cccc}
\hline Sample & Added pb ions $\left(\mathrm{mg} \cdot \mathrm{L}^{-1}\right)$ & $\mathrm{RSD}(\%)$ & Removal\% \\
\hline Tap water (1) & 0 & 0.11 & - \\
Tap water (2) & 5 & 0.33 & 99 \\
Tap water (3) & 10 & 0.21 & 97.3 \\
Tap water (4) & 15 & 0.17 & 96.8 \\
\hline
\end{tabular}

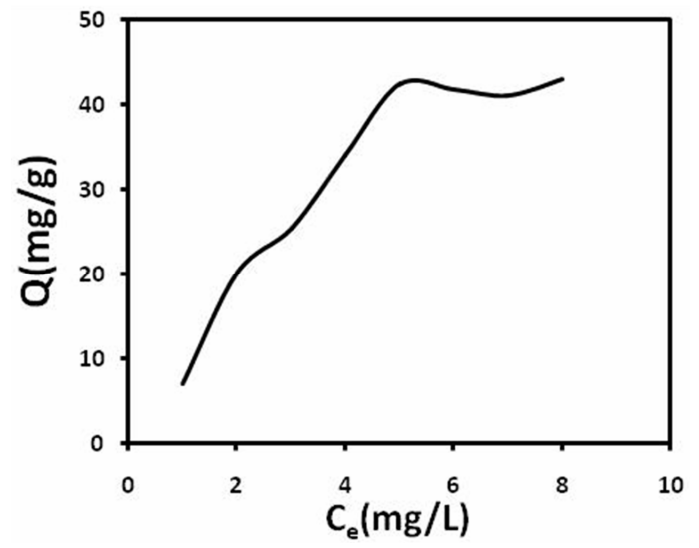

Figure 8. Adsorption isotherm of pb(II) ion on MWCNTTAA.

of ion metals. In the present work, functionalized MWCNTs with tris (2-aminoethyl) amine as the sorbent was prepared by carboxylation and then amidation reactions. This adsorbent was applied for removal of $\mathrm{pb}(\mathrm{II})$ ions from water samples and the following results can be drawn:

The main reason for lead adsorption on the surface of the sorbent originates from sharing of lone ion pair of amine groups to lead ions.

- The solution $\mathrm{pH}$ has the main role in lead adsorption. At $\mathrm{pH}=5.7-6$, complete adsorption of lead occurred.

- Adsorption-desorption cycles can be applied for 4 times by MWCNTs-TAA, which means the ability of the sorbent was not exhausted.

- Adsorption experiments of real samples showed that the sorbent has a favorable potential for removal of $\mathrm{pb}^{2+}$ from waste water.

- In comparison to other heavy metal ions $(\mathrm{Cu}, \mathrm{Ni}, \mathrm{Co}$, $\mathrm{Mn}$, and $\mathrm{Zn}$ ), lead showed higher affinity due to the first stability constant of $\mathrm{pb}$ (II) ion hydroxide.

- It was found that sorption isotherm was better described by Langmuir isotherm. The maximum adsorption capacity value for $\mathrm{pb}^{2+}$ with MWCNTs-TAA (from the Langmuir equation) was $71 \mathrm{mg} / \mathrm{g}$.

\section{REFERENCES}

[1] E. T. Thostenson, Z. Ren and T.-W. Chou, "Advances in the Science Technology of Carbon Nanotubes and Their Composites: A Review," Composites Science and Technology, Vol. 61, No. 13, 2001, pp. 1899-1912. doi:10.1016/S0266-3538(01)00094-X

[2] F. Augusto, E. Carasek and R. Gomes, "New Sorbents for Extraction and Microextraction Techniques," Journal of Chromatography A, Vol. 1217, No. 16, 2010, pp. 25332542. doi:10.1016/j.chroma.2009.12.033

[3] K. Balasubramanian and M. Burghard, "Electrochemi- 
cally Functionalized Carbon Nanotubes for Device Applications," Journal of Materials Chemistry, Vol. 18, No. 26, 2008, pp. 3071-3083. doi:10.1039/b718262g

[4] X. Ren, C. Chen, M. Nagatsu and X. Wang, "Carbon Nanotubes in Environmental Pollution Management, A Review," Chemical Engineering Journal, Vol. 170, No. 2-3, 2011, pp. 395-410. doi:10.1016/j.cej.2010.08.045

[5] S. Z. Mohammadi, D. Afzali and D. Pourtalebi, "Flame Atomic Absorption Spectrometric Determination of Trace Amounts of Lead, Cadmium and Nickel in Different Matrixes after Solid Phase Extraction on Modified Multiwalled Carbon Nanotubes," Journal of Chemistry, Vol. 893, 2010, pp. 662-668.

[6] A. Speltini, D. Merli and A. Profumo, "Carbon Nanotubes: Purification, Functionalization and Analytical Application as Stationary Phases for Choromatografic Separation," Scientifica Acta, Vol. 5, No. 1, 2011, pp. 3-11.

[7] H. Amjad El-Sheikh and J. A. Sweileh, "Recent Application of Nanotubes in Solid Phase Extraction and Preconcentration: A Review," Jordan Journal of Chemistry, Vol. 6, No. 1, 2011, pp. 1-16.

[8] K. Pyrzynska, "Application of Carbon Sorbents for the Concentration and Separation of Metal Ions," Analytical sciences, Vol. 23, 2007, pp. 631-637. doi:10.2116/analsci.23.631

[9] X. Liu, Y. Ji, Y. Zhang, H. Zhang and M. Liu, “ Oxidized Multiwalled Carbon Nanotubes as a Novel Solid-Phase Micro Extraction Fiber for Determination of Phenols in Aqueous Samples," Journal of chromatography A, Vol. 1165, No. 1-2, 2007, pp. 10-17. doi:10.1016/j.chroma.2007.07.057

[10] H. Katsomata, T. Matsomot, S. Kaneko, T. Susuki and K. Ohata, "Preconcentration of Diazinon Using Multiwalled Carbon Nanotubes as Solid Phase Extraction Adsorbents," Microchemical Journal, Vol. 88, No. 1, 2008, pp. 82-86. doi:10.1016/j.microc.2007.10.002

[11] J. Deng, Y. Shao, N. Gao, Y. Deng, C. Tan, S. Zhou and $\mathrm{X}$. Hu, "Multiwalled Carbon Nanotubes as Adsorbents for Removal of Herbicide Diuron from Aqueous Solution," Chemical Engineering Journal, Vol. 193, 2012, pp. 339347.

[12] Y. Al-Degs, M. A. Al-Ghouti and A. H, El-Sheikh, "Simultaneous Determination of Pesticides at Trace Levels in Water Using Multiwalled Carbon Nanotubes as Solidphase Extractant and Multivariate Calibration," Journal of Hazardous Materials, Vol. 169, No. 1-3, 2009, pp. 128-135. doi:10.1016/j.jhazmat.2009.03.065

[13] L. M. Ravelo-Perez, J. Hernández-Borges and M. A. Rodríguez-Deigado, "Multi-Walled Carbon Nanotubes as Efficient Solid-Phase Extraction Materials of Organophosphorus Pesticides from Apple, Grape, Orange and Pineapple Fruit Juices," Journal of Chromatography A, Vol. 1211, No. 1-2, 2008, pp. 33-42. doi:10.1016/j.chroma.2008.09.084

[14] S. Ghaseminezhad, D. Afzali and M. A. Taher, "Flame Atomic Adsorption Spectrometry for the Determination of Trace Amount of Rhodium after Separation and Preconcentration onto Modified Multiwalled Carbon Nano- tubes as a New Solid Sorbent," Talanta, Vol. 80, No. 1, 2009, pp. 168-172. doi:10.1016/i.talanta.2009.06.049

[15] A. H. El-Sheikh, J. A. Sweileh and Y. S. Al-Degs, "Effect of Dimentions of Multi-Walled Carbon Nanotubes on Its Enrichment Efficiency of Metal Ions from Environmental Waters," Analytica Chimica Acta, Vol. 604, No. 2, 2007 pp. 119-126. doi:10.1016/j.aca.2007.10.009

[16] K. Pill, E. M. Cukrowska and N. J. Coville, "MultiWalled Carbon Nanotubes as Adsorbents for the Removal of Parts per Billion Levels of Hexavalent Chromium from Aqueous Solution," Journal of Hazardous Materials, Vol. 166, No. 2-3, 2009, pp. 1067-1075. doi:10.1016/j.jhazmat.2008.12.011

[17] Y.-J. Xu, R. Arrigo, X. Liu and D.-S. Su, "Characterization and Use of Functionalized Carbon Nanotubes for the Adsorption of Heavy Metal Anions," New Carbon Materials, Vol. 26, No. 1, 2011, pp. 57-62.

[18] S. Yang, J. Li, D. Shao, J. Hu and X. Wang, “Adsorption of $\mathrm{Ni}(\mathrm{II})$ on Multi-Walled Carbon Nanotubes: Effect of Contact Time, pH, Foreign Ions and PAA," Journal of Hazardous Materials, Vol. 166, No. 1, 2009, pp. 109-116. doi:10.1016/j.jhazmat.2008.11.003

[19] D. Xu, X. Tan, C. Chen and X. Wang, "Removal of Pb (II) from Aqueous Solution by Oxidized Multiwalled Carbon Nanotubes," Journal of Hazardous Materials, Vol. 154, No. 1-3, 2008, pp. 407-416. doi:10.1016/j.jhazmat.2007.10.059

[20] R. Li, X. Chang, Z. Li, Z. Zang, Z. Hu, D. Li and Z. Tu, "Multiwalled Carbon Nanotubes Modified with 2-Aminobenzothiazole Modified for Uniquely Selective SolidPhase Extraction and Determination of $\mathrm{Pb}$ (II) Ion in Water Samples," Microchimica Acta, Vol. 172, No. 3-4, 2011, pp. 269-276. doi:10.1007/s00604-010-0488-9

[21] A. Stafiej and K. Pyrzynska, "Solid Phase Extraction of Metal Ions Using Carbon Nanotubes," Microchemical Journal, Vol. 89, No. 1, 2008, pp. 29-33. doi:10.1016/j.microc.2007.11.001

[22] N. G. Sahoo, S. Rana, J. W. Cho, L. Li and S. H. Chan, "Polymer Nanocomposites Based on Functionalized Carbon Nanotubes," progress in Polymer Science, Vol. 35, No. 7, 2010, pp. 837-867.

[23] V. Datsyuk, M. Kalyva, K. Papagelis, J. Parthenios and D. Tasis, "Chemical Oxidation of Multiwalled Carbon Nanotubes," Carbon, Vol. 46, No. 6, 2008, pp. 833-840. doi:10.1016/j.carbon.2008.02.012

[24] Z. Wang, M. D. Shirley, S. T. Meikle and R. L. D. Whitby, "The Surface Acidity of Acid Oxidized Multiwalled Carbon Nanotubes and the Influence of in-Situ Generated Fulvic Acids on Their Stability in Aqueous Dispersions," Carbon, Vol. 47, No. 1, 2009, pp. 73-79. doi:10.1016/i.carbon.2008.09.038

[25] J. L. Vicente, A. Albesa, J. L. Lianos, E. S. Flores and A. E. Fertitta, "Effect of Acid Oxidation Treatment on Adsorption Properties of Arc-Discharge Synthesized Multiwall Carbon Nanotubes," Journal of the Argentine Chemical Society, Vol. 98, 2011, pp.29-38.

[26] D. Afzali and A. Mostafafavi, "Potential of Modified Multiwalled Carbon Nanotubes with 1-(2-Pyridylazo)-2- 
naphtol as a New Solid Sorbent for the Preconcentration of Trace Amounts of Cobalt(II) Ion," Analytical Sciences, Vol. 24, No. 9, 2008, pp. 1135-1139. doi:10.2116/analsci.24.1135

[27] H. Tavallali, D. Abdardideh, M. Aalaei and S. Zahmatkesh, "New Application of Chemically Modified Multiwalled Carbon Nanotubes with Thiosemicarbazide as a Sorbent for Separation and Preconcentration of Trace Amounts of $\mathrm{Co}(\mathrm{II}), \mathrm{Cu}(\mathrm{II})$, and $\mathrm{Zn}(\mathrm{II})$ in Environmental and Biological Samples Prior to Determination by Flame Atomic Absorption Spectrometry," Journal of the Chinese Chemical Society, Vol. 58, No. 6, 2011, pp. 1-7.

[28] Y. Cui, Z.-J. Hu, J. X. Yang and H. W. Gao, "Novel Phenyl-Iminodiacetic Acid Grafted Multiwalled Carbon Nanotubes for Solid Phase Extraction of Iron, Copper and Lead Ions from Aqueous Medium," Microchimica Acta, Vol. 176, No. 5, 2012, 359-367. doi:10.1007/s00604-011-0725-x

[29] G. D. Vukovic and A. D. Marinkovic, "Removal of Cadmium from Aqeous Solutions by Oxidized and Ethylenediamine-Functionalized Multi-Walled Carbon Nanotubes," Chemical Engineering Journal, Vol. 15, 2011, pp. 238248.

[30] G. D. Vukovic, A. D. Marinkovic and S. D. Skapin, "Removal of $\mathrm{Pb}(\mathrm{II})$ from Aqueous Solution by Amino Multiwalled Carbon Nanotubes," Chemical Engineering Journal, Vol. 173, No. 3, 2011, pp. 855-865. doi:10.1016/j.cej.2011.08.036

[31] M. R. Nabid, R. Sedghi and A. Bagheri, "Preparation and Application of Poly(2-amino thiophenol )/MWCNTs Nanocamposite for Adsorption and Separation of Cadmium and Lead Ions via Solid Phase Extraction," Journal of Hazardous Materials, Vol. 203-204, 2012, pp. 93-100. doi:10.1016/j.jhazmat.2011.11.096

[32] Y. Cui, S. Liu, Z.-J. Hu and X.-H. Liu, "Solid-Phase Extraction of Lead $(\|)$ Ions Using Multiwalled Carbon Nanotubes Grafted with Tris (2-Aminoethyl)Amine," Microchimica Acta, Vol. 174, No. 1-2, 2011, pp. 107-113. doi:10.1007/s00604-011-0601-8

[33] A. Afkhami, M. Saber-Tehrani and H. Bagheri, "Simultaneous Removal of Heavy-Metal Ions in Wastewater Samples Using Nanoalumina Modified with 2,4-Dinitrophenylhydrazine," Journal of Hazardous Materials, Vol. 181 , No. 1-3, 2010, pp. 836-844. doi:10.1016/j.jhazmat.2010.05.089

[34] I. D. Rosca, F. Watari, M. Uo and T. Akasaka, "Oxidation of Multiwalled Carbon Nanotubes by Nitric Acid," Carbon, Vol. 43, No. 15, 2005, pp. 3124-3131. doi:10.1016/i.carbon.2005.06.019

[35] C. Lu and H. Chiu, "Adsorption of Zinc(II) from Water with Purified Carbon Nanotubes," Chemical Engineering Science, Vol. 61, No. 4, 2006, pp. 1138-1145.

[36] K. Pyrzynska, "Carbon Nanostructures for Separation, Pre- concentration and Speciation of Metal Ions," Trends in Analytical Chemistry, Vol. 29, No. 7, 2010, pp. 718-727. doi:10.1016/j.trac.2010.03.013

[37] A. Afkhami, M. Saber-Tehrani and H. Bagheri, "Flame Atomic Absorption Spectrometric Determination of Trace Amounts of $\mathrm{pb}$ (II) and $\mathrm{Cr}$ (III) in Biological, Food and Environmental Samples after Preconcentration by Modified Nano-Alumina," Microchimica Acta, Vol. 172, No. 1-2, 2011, pp. 125-136. doi:10.1007/s00604-010-0478-y

[38] C.-H. Weng, "Modeling Pb(II) Adsorption onto Sandy Loam Soil," Journal of Collid and Interface Science, Vol. 272, No. 2, 2004, pp. 262-270.

[39] C.-H. Wu, "Studies of the Equilibrium and Thermodynamics of the Adsorption of $\mathrm{Cu}^{2+}$ onto As-Produced and Modified Carbon Nanotubes," Journal of Colloid and Interface Science, Vol. 311, No. 2, 2007, pp. 338-346. doi:10.1016/j.jcis.2007.02.077

[40] N. A. Kabbashi, M. A. Atieh and A. Al-Mamun, "Kinetic Adsorption of Application of Carbon Nanotubes for pb(II) Removal from Aqueous Solution," Journal of Environmental Sciences, Vol. 21, No. 4, 2009, pp. 539-544.

[41] C. Chen and X. Wang, "Adsorption of Ni(II) from Aqueous Solution Using Oxidized Multiwall Carbon Nanotubes," Industrial \& Engineering Chemistry Research, Vol. 45, No. 26, 2006, pp. 9144-9149. doi:10.1021/ie060791z

[42] S. A. Dastgheib and D. A. Rocktraw, "A Model for the Adsorption of Single Metal Ion Solutes in Aqueous Solution onto Activated Carbon Produced from Pecan Shells," Carbon, Vol. 40, No. 11, 2002, pp. 1843-1851. doi:10.1016/S0008-6223(02)00037-4

[43] A. Islam, M. A. Laskar and A. Ahmad, "Characterization of a Novel Chelating Resin of Enhanced Hydrophilicity and Its Analytical Utility for Preconcentration of Trace Metal Ions," Talanta, Vol. 81, No. 4, 2010, pp. 1772 1780. doi:10.1016/j.talanta.2010.03.035

[44] M. Imamoglu and O. Tekir, "Removal of Copper(II) and Lead(II) Ions from Aqueous Solutions by Adsorption on Activated Carbon from a New Precursor Hazelnut Husks," Desalination, Vol. 228, No. 1-3, 2008, pp. 108-113. doi:10.1016/j.desal.2007.08.011

[45] F. Xie, X. Lin, X. Wu and Z. Xie, "Solid Phase Extraction of Lead(II), Copper(II), Cadmium(II) and Nickel(II) Using Gallic Acid Modified Silica Gel Prior to Determination by Flame Atomic Absorption Spectrometry," Talanta, Vol. 74, No. 4, pp. 836-843. doi:10.1016/j.talanta.2007.07.018

[46] Y. Cui, X. Chang, Y. Zhai and H. Zhu, "ICP-AES Determination of Trace Elements after Preconcentrated with p-Dimethylaminobenaldehyde-Modified Nanometer $\mathrm{SiO}_{2}$ from Sample Solution," Microchemical Journal, Vol. 83, No. 1, 2006, pp. 35-41. doi:10.1016/i.microc.2006.01.020 